\title{
エマルジョンの安定性に及ぼす顔料の影響
}

\section{藤戸 武*·永辠稔夫**村田哲也*'中村真敏*}

\section{The Effect of Pigments on the Stability of Emulsions}

Takeshi Fujito*, Toshio Nagamine*, Tetsuya Murata* and Masatoshi Nakamura*

It was shown through experiments that pigments addition in emulsions can be related to emulsion stability.

The stability evaluation was conducted by preparing emulsions containing nonioric emulsifiers, adding thereto pigments (oxide red of iron, ochre, clay and carbon black from 0.1 to $10 \%$ for the quantity of emulsions) and keeping such mixtures at the temperatures ranging from $50^{\circ}$ to $80^{\circ}$ for an hour.

Emulsion stability is affected considerably by pigments addition and in most cases is broken. However, it was recognized that the degrees of the affection vary according to the kind and concentration of emulsifiers, the kind of oils, etc., which compose the emulsions. Some differences: in the effect are caused by the kind of the pigments added. The $\mathrm{pH}$ value also has some effect on the breaking state of emulsions.

It is generally noted that the higher temperature is retained, the more outstanding this phenomenon of emulsion breakage becomes.

\section{1 緒言}

エマルジョンの安定性に関する報告は数多いが，その 多くは電解質の添加1),2), 乳化剂の組合せ3)・4), ビタ ミ ン, ホルモン等特殊成分の添加 ${ }^{5)}$, 温度の変化 ${ }^{6)}$ 等の影 響について論じたものであって，顔料がエマルジョン中 に加えられた場合の変化についての研究は非常に少い。

一方，化粧品界においては，エマルジョンに顔料究加 えた型の商品がファンデーションをはじめとして大きな 比重を占めており，エマルジョンと顔料との相互関係は 重要な問題の一つである。

我々は以前から顔料の添加がエマルジョンの安定性に どのような影響を与えるかについて研究を続けてきた が，得られた二・三の知見をここに報告する。

\section{2 実験}

\section{2-1 エマルジョンの調製}

顔料添加の影響をより明確に把握するために，エマル ジョンは簡単な組成のものを用いた。単一の油 $10 \%$, 蒸 溜水 $90 \%$ ，これに乳化剂を油に対して $10 \%$ 万至 $30 \%$ 使用 し, 常法により乳化した後, ホモジナイザーで処理し

* 株式会社ピアス（大阪市大淀区豊崎西通 1 -18）

* PIAS CO., LTD.
た。

乳化剤としては次のものを用いた。

1) ポリオキシェチレンオレイルアルコールエーテル 一エチレンオキサイド平均 7 モル附加物

(以下B-7と略称)

2) ポリオキシェチレンソルビトールモノラウレート 一エチレンオキサイド平均 6 モル附加物と ポリオキシエチレンソルビトール キサステアレ

ート—エチレンオキサイド平均 6 モル附加物との 混合物（以下それぞれ G-1, G-6 と略称, 混合比 $2: 3)$

3) ポリオキシエチレソセチルアルコールエーテルー エチレンオキサイド平均 2 モル附加物と同じく平均 20 モル附加物との混合物（以下それぞれ C-2, C-20 と略称, 混合比 $11: 9)$

これらの乳化剤はいずれも HLB 值は約 8 であり，調 製したエマルジョンはそれ自身，以下に述べる実験条件 のもとで十分に安定である。

このようにして調製したエマルジョンに，顔料を重量 で 0.1 乃至 $10 \%$ 加え, ライカイ機で 5 分間練合した後, 試験管にとり実験に供した。

\section{2-2 使用した顔料}

顔料は化粧品用ベンガラ, エローオーカー, クレー, 
カーボンブラックの四種を用いた。これら顔料の特性值

它 Table-1 に示す。

Table-1 Characteristics of pigments

\begin{tabular}{l|c|c|c|c}
\hline Kinds of & \multicolumn{4}{|c}{ Characteristics } \\
\cline { 2 - 5 } pigment & $\begin{array}{c}\text { Mean } \\
\text { particle } \\
\text { diameter }(\mu)\end{array}$ & $\begin{array}{c}\text { Specific } \\
\text { gravity }\end{array}$ & $\mathrm{pH}$ & $\begin{array}{l}\text { Oil adsoption } \\
(\mathrm{ml} / 100)\end{array}$ \\
\hline $\begin{array}{l}\text { Oxide red } \\
\text { of iron }\end{array}$ & 1.2 & 5.1 & 6.5 & 45 \\
Ochre & 1.0 & 3.0 & 6.1 & 50 \\
Clay & 1.5 & 2.7 & 3.5 & 47 \\
$\begin{array}{l}\text { Carbon } \\
\text { black* }\end{array}$ & 0.03 & 2.1 & 4.6 & 123 \\
\hline
\end{tabular}

* Channel type

顔料は塩等の影響をさけるために, 熱水で 1 時間処理 し，室温で乾燥して用いた。

\section{2-3 顔料の影響の評価}

この実験では，加温状態での現象を観察することによ り，エマルジョンがどの程度顔料に影響されるかをとら えることとした。即ち, 顔料を加えたエマルジョンを, $50^{\circ}, 60^{\circ}, 70^{\circ}, 80^{\circ}$ に保ち, 1 時間後の状態により顔料 の影響の程度を評価した。

\section{3 結果および考察}

\section{3-1 顔料の種類と温度}

エマルジョンとして，流動パラフィン $10 \%$ ，蒸溜水 90 \%, これに乳化剤として B-7 索流動パラフィンに対し て20\%使用したものを用いて，各温度における顔料の工 マルジョンへの影響を゙調べた。結果它Table-2 に示す。 顔料の種類により差はあるが，50，60を除き，いずれ もエマルジョンの破壊が起こり，温度の上昇に伴って破 壊状態の大きくなることが認められる。

\section{3-2 乳化剂の種類と濃度}

乳化剂の種類と濃度を変化させた場合の, 顔料添加の 影響を $80^{\circ}$ において調べた。流動パラフィン $10 \%$ ，蒸溜 水 $90 \%$ の系において，乳化剂濃度をそれぞれ流動パラフ ィン量に対して $10 \% ， 20 \% ， 30 \%$ と変化させた場合の結 果を Table-3，また破壊状態の代表例を Fig-1～6 に示 于。

乳化剂の種類によって破壊の様相がかなり異なり，一 般にB-7の系では乳化鼡濃度が増すにつれて破壊は小さ くなり，G-1/G-6の場合には，これとは逆に乳化剤濃 度が増すにつれて破壊の大きくなっていることがみられ る。なお C-2/C-20ではいずれの場合にも破壊を認めな かったので，表に記載することを省略した。

Table-2 Effects of temperature and several pigments on emulsion stability

\begin{tabular}{|c|c|c|c|c|c|c|c|c|c|c|c|}
\hline \multirow{2}{*}{ Kinds of pigment } & \multirow{2}{*}{$\begin{array}{c}\text { Temp. } \\
\left({ }^{\circ} \mathrm{C}\right)\end{array}$} & \multicolumn{10}{|c|}{ Amount of pigments (\%) } \\
\hline & & 0.1 & 0.5 & 1 & 2 & 3 & 4 & 5 & 6 & 8 & 10 \\
\hline \multirow{4}{*}{ Oxide red of iron } & 50 & - & - & - & - & - & - & - & - & - & $-*$ \\
\hline & 60 & - & - & - & - & - & - & - & - & - & - \\
\hline & 70 & - & - & - & + & $H$ & $H$ & H & $H$ & H & $H$ \\
\hline & 80 & - & H & $H$ & H & $H$ & $H$ & H & H & $H$ & $H$ \\
\hline \multirow{4}{*}{ Ochre } & 50 & - & - & - & - & - & - & - & - & - & - \\
\hline & 60 & - & - & - & - & - & - & - & - & - & - \\
\hline & 70 & - & - & - & - & + & $H$ & $H$ & $H$ & H & $H$ \\
\hline & 80 & - & + & $H$ & $H$ & H & $H$ & $H$ & $H$ & $H *$ & $H *$ \\
\hline \multirow{4}{*}{ Clay } & 50 & - & - & - & - & - & - & - & - & - & - \\
\hline & 60 & - & - & - & - & - & - & - & - & - & - \\
\hline & 70 & - & + & + & $H$ & $H$ & $H$ & $H$ & $H$ & $H$ & $H$ \\
\hline & 80 & - & $H$ & $H$ & $H$ & $H$ & $*$ & $*$ & $*$ & $*$ & $*$ \\
\hline \multirow{4}{*}{ Carbon black } & 50 & - & - . & - & - & - & - & - & - & - & - \\
\hline & 60 & - & - & - & - & - & - & - & - & - & - \\
\hline & 70 & - & H & $+*$ & $+*$ & $+*$ & $+*$ & $H *$ & $H^{*}$ & $*$ & $*$ \\
\hline & 80 & - & - & $H *$ & $H^{*}$ & $H *$ & $H^{*}$ & $H *$ & $H^{*}$ & $*$ & $* *$ \\
\hline
\end{tabular}

* Eeach symbol shows the breaking phenomenon of emulsions as Fig-7, but the sedimentation layer of pigments was excepted. 
Table-3 Effects of the emulsifier concentration on emulsion stability

\begin{tabular}{|c|c|c|c|c|c|c|c|c|c|c|c|c|}
\hline \multirow{2}{*}{ Kinds of pigment } & \multirow{2}{*}{$\left|\begin{array}{l}\text { Amount of } \\
\text { emulsifier }\end{array}\right|$} & \multirow{2}{*}{\begin{tabular}{|c|} 
Kinds of \\
emulsifier
\end{tabular}} & \multicolumn{8}{|c|}{ Amount of pigments (\%) } & \multicolumn{2}{|l|}{$i$} \\
\hline & & & 0.1 & 0.5 & 1 & 2 & 3 & 4 & 5 & 6 & 8 & 10 \\
\hline \multirow{6}{*}{ Oxide red of iron } & \multirow[b]{2}{*}{10} & $\mathrm{~B}-7$ & - & $+*$ & $H^{*}$ & $H *$ & $+*$ & $+*$ & H* & $+*$ & $+*$ & $H *$ \\
\hline & & $G-1 / G-6$ & - & - & - & - & - & - & - & - & - & - \\
\hline & \multirow[b]{2}{*}{20} & B -7 & - & $H$ & $H$ & $H$ & $H$ & $H$ & $H$ & H & $H$ & H \\
\hline & & $G-1 / G-6$ & - & - & - & - & - & $*$ & $*$ & $*$ & $*$ & $*$ \\
\hline & \multirow[b]{2}{*}{30} & $\mathrm{~B}-7$ & - & - & - & + & + & + & + & + & + & + \\
\hline & & $\mathrm{G}-1 / \mathrm{G}-6$ & - & - & $+*$ & $H *$ & $*$ & $*$ & $*$ & $*$ & $*$ & $*$ \\
\hline \multirow{6}{*}{ Ochre } & \multirow[b]{2}{*}{10} & $\mathrm{~B}-7$ & - & - & - & + & $H^{*}$ & $H *$ & $H^{*}$ & $+*$ & $+*$ & $H *$ \\
\hline & & $\mathrm{G}-1 / \mathrm{G}-6$ & - & - & - & - & - & + & + & + & + & + \\
\hline & \multirow{2}{*}{20} & $\mathrm{~B}-7$ & - & + & $H$ & $H$ & $H$ & $H$ & $H$ & $H$ & $H *$ & $H *$ \\
\hline & & $G-1 / G-6$ & - & - & - & - & - & + & + & $H$ & $H^{*}$ & $H^{*}$ \\
\hline & \multirow[b]{2}{*}{30} & $\mathrm{~B}-7$ & - & - & - & - & - & + & + & + & + & + \\
\hline & & $\mathrm{G}-1 / \mathrm{G}-6$ & - & - & - & - & $+*$ & $H *$ & $*$ & $*$ & $*$ & $*$ \\
\hline \multirow{6}{*}{ Clay } & \multirow[b]{2}{*}{10} & $\mathrm{~B}-7$ & - & $H *$ & $H *$ & $H *$ & $*$ & $*$ & $*$ & $*$ & $*$ & $*$ \\
\hline & & $\mathrm{G}-1 / \mathrm{G}-6$ & - & - & - & - & - & $+*$ & $+*$ & $H *$ & $H *$ & $H^{*}$ \\
\hline & \multirow[b]{2}{*}{20} & $\mathrm{~B}-7$ & - & $H$ & $H$ & $H$ & $H$ & $*$ & $*$ & $*$ & $*$ & $*$ \\
\hline & & $\mathrm{G}-1 / \mathrm{G}-6$ & - & - & - & - & - & $H *$ & $H^{*}$ & $+*$ & $*$ & $*$ \\
\hline & \multirow[b]{2}{*}{30} & $\mathrm{~B}-7$ & - & + & + & $H$ & H & H & H & $H$ & $H$ & H \\
\hline & & $G-1 / G-6$ & - & - & - & - & $H^{*}$ & $H *$ & $H *$ & $*$ & $*$ & $*$ \\
\hline \multirow{6}{*}{ Carbon black } & \multirow[b]{2}{*}{10} & B -7 & - & - & - & $H *$ & $+*$ & $H^{*}$ & $H *$ & $*$ & $* *$ & $* *$ \\
\hline & & $\mathrm{G}-1 / \mathrm{G}-6$ & - & 一 & - & - & - & - & - & - & $* *$ & $* *$ \\
\hline & \multirow[b]{2}{*}{20} & $\mathrm{~B}-7$ & - & - & $H *$ & $H *$ & $H *$ & $+*$ & $H *$ & $H *$ & * & $* *$ \\
\hline & & $\mathrm{G}-1 / \mathrm{G}-6$ & - & - & - & - & $H *$ & $H^{*}$ & $+*$ & $H *$ & $*$ & $* *$ \\
\hline & \multirow[b]{2}{*}{30} & $\mathrm{~B}-7$ & - & - & - & + & $H$ & $H *$ & $H^{*}$ & $H *$ & * & $*$ \\
\hline & & $G-1 / G-6$ & - & - & - & - & $H *$ & $H *$ & H* & $+*$ & $* *$ & $* *$ \\
\hline
\end{tabular}

Representative breaking state of emulsion

Fig-1 $\quad$ B $-7 \quad 10 \%$

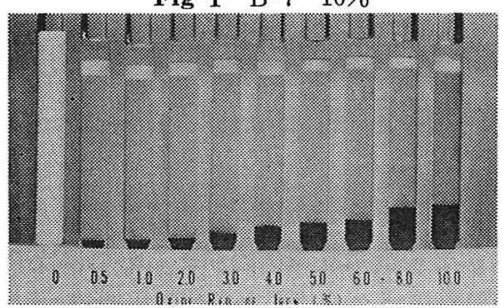

Fig-4 G-1/G-6 10\%

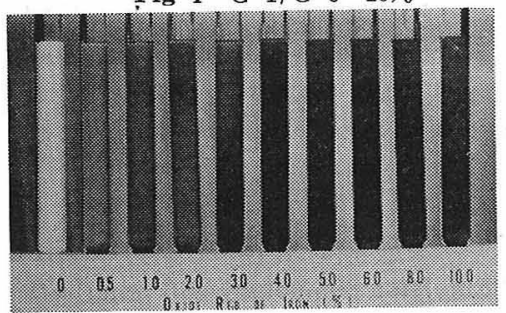

$\begin{array}{lll}\text { Fig-2 } & \mathrm{B}-7 \quad 20 \%\end{array}$

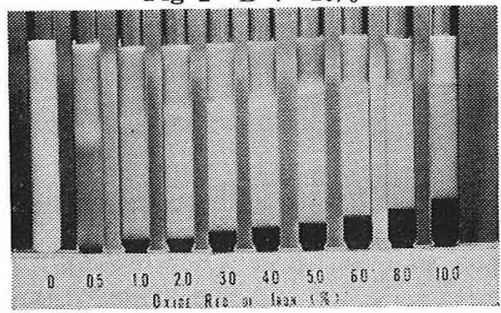

Fig-5 G-1/G-6 $20 \%$

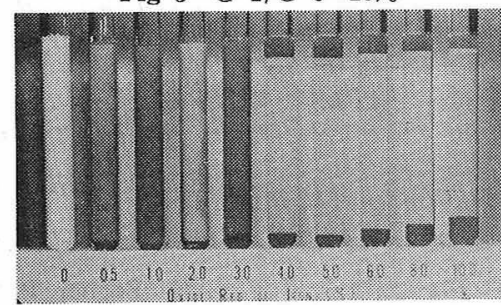

Fig-3 $\quad$ B $-7 \quad 30 \%$

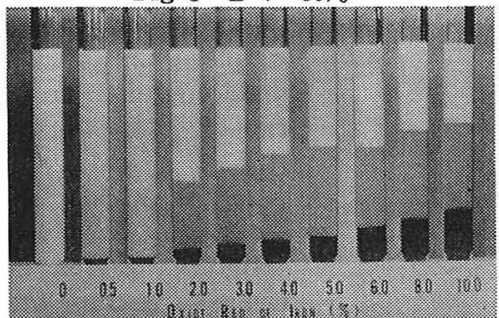

Fig-6 $\quad$ G $-1 / G-6 \quad 30 \%$

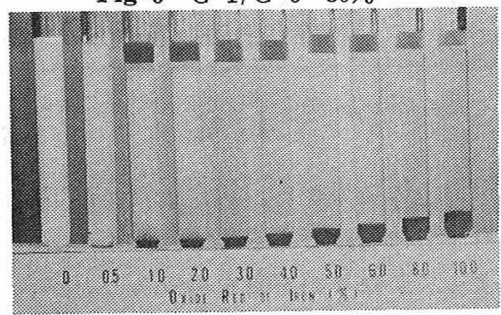




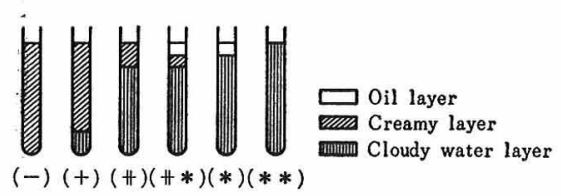

Fig-7

\section{3-3 油}

化粧品にしばしば用いられる油の中から，イソプロピ ルミリステートとオレイルアルコールを選び，同様の実 験を行なった結果を Table-4 に示す。油の量は10\%, 乳 化剂はB-7劣油に対して $20 \%$ ，温度は $80^{\circ}$ である。
油相の变化は明らかにエマルジョンの安定性に影響を 及汇し, 流動パラフィンの場合に比較して破壊の程度が 小さくなる。オレイルアルコールでは更に破壊を受け難 くなり, 特にベンガラの系では全く破壊がみられない。 3-4 $\mathrm{pH}$

流動パラフィン $10 \%$, 乳化郕は油に対して $20 \%$, 顔料 は全量に対して $5 \%$ を添加し， $80^{\circ}$ において $\mathrm{pH}$ を変化 させた場合の結果を Table-5 到示す。B-7および C-2/ C-20 の場合には $\mathrm{pH}$ の变化の影響は認められないが, G-1/G-6 の場合には中性乃至弱アルカリ性においてエ マルジョンの破壊の起こらないことが認められる。

Table-4 Effects of oils on emulsion stability

\begin{tabular}{|c|c|c|c|c|c|c|c|c|c|c|c|}
\hline \multirow{2}{*}{ Kinds of oil } & \multirow{2}{*}{ Kinds of pigment } & \multicolumn{10}{|c|}{ Amount of pigments (\%) } \\
\hline & & 0.1 & 0.5 & 1 & 2 & 3 & 4 & 5 & 6 & 8 & 10 \\
\hline \multirow{4}{*}{ Isopropyl myristate } & Oxide red of iron & - & - & - & + & + & + & + & + & + & + \\
\hline & Ochre & - & + & + & + & + & + & + & + & + & + \\
\hline & Clay & - & - & - & - & - & - & - & - & $H^{*}$ & H* \\
\hline & Carbon black & - & - & - & - & - & - & - & * & $* *$ & $* *$ \\
\hline \multirow{4}{*}{ Oleyl alcohol } & Oxide red of iron & - & - & - & - & - & - & - & - & - & 一 \\
\hline & Ochre & - & - & - & 一 & - & - & + & + & + & + \\
\hline & Clay & - & - & 一 & - & 一 & - & - & + & + & + \\
\hline & Carbon black & - & - & - & - & - & - & - & H & $* *$ & $* *$ \\
\hline
\end{tabular}

Table-5 Effect of $\mathrm{pH}$ on emulsion stability

\begin{tabular}{|c|c|c|c|c|}
\hline \multirow{2}{*}{$\begin{array}{l}\text { Kinds of } \\
\text { emulsifier }\end{array}$} & \multirow{2}{*}{ Kinds of pigment } & \multicolumn{3}{|c|}{$\mathrm{pH}$} \\
\hline & & 5 & 7 & 8 \\
\hline \multirow{4}{*}{$\mathrm{B}-7$} & Oxide red of iron & H & H & H \\
\hline & Ochre & $H$ & H & H \\
\hline & Clay & $*$ & $*$ & $*$ \\
\hline & Carbon black & H* & $H^{*}$ & $H^{*}$ \\
\hline \multirow{4}{*}{$C-2 / C-20$} & Oxide red of iron & - & - & 一 \\
\hline & Ochre & - & - & - \\
\hline & Clay & - & - & - \\
\hline & Carbon black & - & - & - \\
\hline \multirow{4}{*}{$\mathrm{G}-1 / \mathrm{G}-6$} & Oxide red of iron & $*$ & 一 & - \\
\hline & Ochre & + & - & - \\
\hline & Clay & $H *$ & - & - \\
\hline & Carbon black & $H *$ & - & - \\
\hline
\end{tabular}

\section{4 総括}

以上の結果から，設定した条件下で，エマルジョン自 身十分に安定であるにも拘らず，顔料を添加することに よってかなりの影響を受けることが判明した。
そして，エマルジョンを構成寸る乳化剂の種類および 濃度によって，あるいは油の種類によって，受ける影響 の程度に相当な差違のあること琴めた。また, 添加し た顔料の種類によっても影響に程度の差を認めた。 $\mathrm{pH}$ の変化もまた，これらの現像に影響を与え，一般に，温 度が高いほど，現象の現われ方が激しくなることをも認 めた。

乙かし，これらの現象に理論的説明を与光るためには 次のようなポイントをより詳細に検討する必要があると 灰えられる。即ち，考光得る可能性としてまず，顔料に よる乳化剤の吸着によってェマルジョンの破壊が起こる のではないか，またその吸着に選択性があるのではない か, 次に添加した顔料がエマルジョンの転相に影響し7,8) 不安定な系を導くのではないかというととなどであり， これらの点については, 今後検討を加えていく予定であ る。

なお，本発表を許可された株式会社ピアス阪本社長に 感謝の意を表します。

\section{文献}

1) Becher, P. "Emulsion technology and practice" 
p.159 (1957), New York, Reinhold Publishing Corp.

2) Shick, M. J. "Nonionic surfactants" p.500 (1967) New York, Marcel Dekker Inc.

3) Becher, P. "Emulsion technology and practice" p.96(1957), New York, Reinhold Publishing Corp.

4) Benerito, R.R., Singleton, W.S., J. Am. Oil Ch em. Soc., 33, 364 (1956)

5) Fr. P. 1, 351, 454 (Feb., 7, 1964)

6) Richardson, E. G., J. Colloid Sci., 5, 404 (1950)

7) Hildebrand, J.H. J. Amer. Chem. Soc. p.2736 (1923)

8) Schulman, J.H., Trans. Faraday Soc., 3,290(19 48) 